\title{
A experiência do sudoeste asiático - Timor-Leste ${ }^{1}$
}

Francisco Martins

Contando com o acolhimento da Universidade Nacional Timor Lorosa'e, o XXVI encontro da AULP foi histórico. Pela primeira vez, em 30 anos de atividade associativa, a associação reuniu em terras timorenses, revelando ser uma oportunidade única para reafirmar a língua portuguesa num país que se comprometeu a impulsionar a promoção da língua portuguesa através da formação inicial e contínua de professores e ainda da expansão do ensino da língua às escolas privadas.

Por sugestão da Universidade Nacional Timor Lorosa'e a agenda do encontro, que decorreu nos dia 29, 30 junho e 1 julho, abordou diversos aspetos em torno do tema "Rotas de signos: mobilidade académica e globalização no espaço da CPLP e Macau". Como já é frequente, este tema foi posteriormente distribuído por várias sessões que resultaram em comunicações com temas diversos. Em algumas dessas comunicações esteve patente o estudo de signos que contam a história de Timor-Leste; outras intervenções refletirão políticas e estratégias de viabilização da mobilidade académica nos países lusófonos. Por fim, alguns oradores viram neste encontro a ocasião para divulgar atuais projetos que poderão servir de exemplo para futuras iniciativas ou até incitar parcerias interuniversitárias.

Os participantes foram recebidos na véspera do Encontro, 28 de junho, com um jantar de boas vindas oferecido pela AULP no Hotel Novo Turismo. Deram as boas vindas o Presidente da AULP, Professor Doutor Rui Martins em representação da Universidade de Macau, o Reitor da UNTL, Professor Doutor Francisco Martins, passando ainda um vídeo elaborado pela UNTL com mensagens de algumas personalidades de relevo de Timor. Junto à piscina, os participantes foram acolhidos de forma calorosa tendo ainda usufruído de música timorense ao vivo. Proporcionou-se ainda que vários representantes dos países de língua portuguesa contribuíssem com uma música, um poema ou uma dança típica do seu país, proporcionando um momento culturalmente rico.

No primeiro dia, a partir das 9h30, decorreram os trabalhos do Conselho de Administração no Hotel Timor, presidido pelo Prof. Doutor Rui Martins, Presidente da AULP em representação do Reitor da Universidade de Macau, com o objetivo da avaliação multilateral do relatório de atividades da Associação das Universidades de Língua Portuguesa (AULP) que incluem a ponderação do prémio Fernão Mendes Pinto 2016 e respetiva avaliação, as atividades de representação externa e

1. Texto construído com base nos comunicados de imprensa elaborados pelo Gabinete de Comunicação da AULP, por ocasião do XXVI Encontro. 
a atividade editorial em curso, para além da atividade corrente da sede internacional, localizada em Lisboa. Particular atenção mereceu o planeamento da atividade associativa para o próximo ano, liderado pela Universidade de Macau, a que se associaram todas as instituições representadas no Conselho. Foi ainda discutido o lançamento da Revista Internacional em Língua Portuguesa (RILP), III Série, n. ${ }^{\circ} 28, n^{\circ} 29$ e no 30 , bem como um balanço dos pedidos de adesão e desfiliação de instituições membro.

Já na entrada do Centro de Convenções de Díli, por volta das 11h30, vários locais aguardavam a chegada dos participantes, para homenagear a sua presença com música e dança tradicional. No interior, antes de dar início à sessão, o coro da UNTL cantou o hino nacional timorense e a marcha da universidade.

Na presença de suas excelências, o Ex-Presidente do Parlamento Nacional da República Democrática de Timor-Leste e Ex-Presidente da Comissão de Preparação da Cimeira da CPLP de 2014, Senhor Doutor Francisco Guterres "Lú-Olo", o Ministro de Estado Coordenador dos Assuntos Sociais e Ministro da Educação da República Democrática de Timor-Leste, Dr. António Conceição, o Magnífico Reitor da Universidade Nacional Timor Lorosa'e, Professor Doutor Francisco Martins, o Presidente da Associação das Universidades de Língua Portuguesa (AULP), Professor Doutor Rui Martins em representação do Reitor da Universidade de Macau, e o Professor Doutor Vicente Paulino, da Comissão Organizadora do evento, decorreu a sessão solene de abertura do XXVI Encontro da AULP no Centro de Convenções de Díli (CCD).

O Professor Doutor Rui Martins relembrou que a cooperação entre a AULP e a UNTL não é recente e teve início em novembro de 2001, sendo na altura sustentada pelo então Magnífico Reitor da UNTL, Professor Doutor Benjamin Côrte-Real.

O Professor Doutor Francisco Martins manifestou o seu agradecimento a toda a comunidade académica e científica, salientando o modelo de mobilização para este encontro a que os funcionários, estudantes e docentes da UNTL aderiram entusiasticamente.

Após um almoço oferecido pela UNTL nos jardins do CCD, com música ao vivo local, os participantes foram conduzidos novamente para o interior dando início aos trabalhos.

Terminando o decorrer dos trabalhos do Tema I: Políticas e Estratégias de Viabilização da Mobilidade Académica nos Países Lusófonos, ao final do dia deu-se o lançamento das edições comemorativas da AULP apresentado pelo Professor Doutor Rui Martins e pela Secretária-Geral da AULP, Professora Cristina Montalvão Sarmento.

A Associação das Universidades de Língua Portuguesa decidiu, por ocasião do XXVI Encontro da AULP em Díli, Timor-Leste, publicar uma memória, em 
forma de brochura, "Timor-Leste: Identidade e Território" que recorda a história de Timor-Leste. Assim convidou-se o investigador Professor Doutor Fernando Augusto de Figueiredo, que tem dedicado grande parte da sua vida académica a estudar o país e a sua história, a escrever um artigo original para a prestigiada ocasião.

Nesta obra o investigador recorda os reinos timorenses, falando da presença portuguesa no país, as problemáticas associadas à fronteira marítima, bem como os acontecimentos mais relevantes que levaram a bom porto a independência de Timor-Leste a 20 de maio de 2002.

Oferecido aos membros da AULP e participantes do Encontro, a este opúsculo junta-se ainda a relevante Planta das Operações na Pedra do Cailaco, [CA. 1727], cedida à AULP pelo Arquivo Histórico Ultramarino, que se traduz num desenho anexo a uma carta enviada pelo governador de Timor, António Moniz de Macedo, para o vice-rei de Goa, Saldanha da Gama, em 30 de Abril de 1727. Um valioso documento para a história do país, reproduzido agora para o primeiro Encontro da AULP em Timor, no ano em que completa os 30 anos.

Também decorreu o lançamento do livro fac-símile "Virtudes de algumas plantas, folhas, frutas, cascas e raízes de diferentes árvores e arbustos da tha de Timor", um documento ímpar para a História Natural de Timor-Leste, com desenhos aguarelados que acompanham a descrição exaustiva das plantas referenciadas e a listagem de remédios que delas podem ser obtidos e que eram usados pelas gentes de Timor.

Com mais de 200 académicos dos vários países de língua portuguesa, o primeiro dia do XXVI Encontro da AULP superou as expectativas de todos os presentes.

No segundo dia do Encontro da AULP a decorrer no Centro de Convenções de Díli (CCD), os participantes apresentaram mais de 30 trabalhos, com o objetivo de debater a mobilidade académica e globalização no espaço lusófono.

A primeira sessão, deste segundo dia, foi presidida pelo Magnífico Reitor da Universidade do Porto, Professor Doutor Sebastião Feyo de Azevedo. O início dos trabalhos do Tema II "Ciências: Difusão e Desenvolvimento(s) em Língua Portuguesa" teve início logo pela manhã. O Magnífico Reitor da Universidade Zambeze, Professor Doutor Nobre Roque Santos, foi o primeiro orador e aproveitou a ocasião para apresentar o seu livro "Estruturadores do Discurso na aula de Português em Moçambique", oferecendo exemplares à biblioteca da UNTL.

A Professora Maria Ângela Carrascalão, da Universidade Nacional Timor Lorosa'e, deu a conhecer algumas das dificuldades no ensino superior sentidas pelos alunos de direito da UNTL, salientando a importância do português no ensino em Timor-Leste.

Já a professora Anabela Barros, da Universidade do Minho, falou sobre o multilinguismo e paisagem linguística de Timor-Leste, português, tétum, inglês 
120 | RILP - Revista Internacional em Língua Portuguesa - nº 30 - 2016

e indonésio, bem como as diferenças entre o português europeu e o português de Timor.

A Professora Rita Cadima, do Instituto Politécnico de Leiria, apresentou a plataforma UP2U onde os estudantes podem inscrever-se em cursos online gratuito facilitando e promovendo o ensino superior em língua portuguesa. Em 2 anos registaram inscrições em mais de 80 países, revelando ser uma boa ferramenta para utilizar em qualquer parte do mundo.

O tema III "Rotas de Signos: Sentidos, Migrações e Interculturalidade" foi presidido pelo Magnífico Reitor da Uni Lúrio, Professor Doutor Francisco Noa. Nos vários trabalhos apresentados, existiu maioritariamente a discussão dos signos portugueses em Timor.

No tema IV "Paisagens, Natureza e Cultura", o Professor Doutor Samuel Freitas, da Universidade Nacional Timor Lorosa'e, foi o presidente da sessão. O turismo em Cabo Verde, Alentejo (Portugal), e análise do trabalho do poeta Ruy Cinatty, foram os temas trabalhados.

Após uma pausa para o almoço oferecido pela UNTL, deu-se início aos trabalhos do tema V "Outros Desafios das Instituições de Ensino Superior da AULP”, em que o Vice-Reitor da Universidade de Coimbra, o Professor Doutor Joaquim Ramos de Carvalho, foi o presidente da sessão.

Os assuntos em debate foram diversos. Entre as várias comunicações do período da tarde foi apresentado o projeto UTI-África, pelo Professor Doutor João Sàágua, vice-reitor da Universidade Nova de Lisboa. Já o Professor Sérgio Fonseca contribuiu para a sessão com uma problematização dos desafios do ensino superior privado e da educação multicultural.

Olhando para a rede de enfermagem de saúde da mulher nos países de língua portuguesa, teve-se o contributo da Professora Doutora Maria Leitão, da Escola Superior de Enfermagem de Coimbra, que desafiou todos os membros institucionais da AULP a juntarem-se para contribuírem para o desenvolvimento desta rede.

Com o decorrer dos trabalhos ficou patente a qualidade dos mesmos e a sua relevância para aproximar as várias instituições na resolução dos desafios do ensino superior nos países de língua portuguesa.

Terminada a conferência, a UNTL surpreendeu os participantes no jantar de encerramento, junto ao palco do Centro de Convenções de Díli. Um espetáculo foi montado e vários grupos de música e dança local timorense, animaram a noite.

O Magnífico Reitor da UNTL, Professor Doutor Francisco Martins, proferiu umas palavras de apreço a todos os presentes, revelando estar feliz com o sucesso do Encontro. Já o Professor Doutor Rui Martins, Presidente da AULP em representação da Universidade de Macau, agradeceu a fantástica receção do povo 
timorense, e toda a organização que fizeram do XXVI Encontro uma conferência memorável e uma das melhores da AULP.

Das várias celebrações durante a noite, destaca-se as últimas músicas que encerraram o jantar. Foram chamados ao palco o atual Reitor e os ex-Reitores da UNTL, bem como o Professor Doutor Vicente Paulino, responsável pela Comissão Organizadora da universidade, que cantaram. Os participantes do Encontro foram desafiados a dançarem e, por último, a construírem um círculo em frente ao palco, de mãos dadas, onde mais de 150 dirigentes, reitores, presidentes, professores, investigadores, alunos e membros da organização, mostraram a força do lema da AULP - ex unitate vis (a força está na nossa união).

No último dia, a Assembleia Geral foi presidida pelo Professor Doutor Francisco Martins, anfitrião do XXVI Encontro da AULP e reitor da Universidade Nacional Timor Lorosa'e. O Professor Doutor Rui Martins, Presidente da AULP, em representação da Universidade de Macau, e Vice-reitor da Universidade de Macau, e a Professora Doutora Cristina Montalvão Sarmento, Secretária Geral da AULP, estiveram presentes na mesa que conduziu esta reunião onde foi feito um balanço das atividades associativas. O Professor Doutor Rui Martins agradeceu a calorosa receção da UNTL, em especial ao Senhor Reitor.

Ficou ainda decidido que o próximo Encontro da AULP, o XXVII, teria lugar na Universidade de Campinas (Brasil), em que o representante, Professor Doutor Flávio Ribeiro de Oliveira, aproveitou a ocasião para convidar todos os presentes a ir à próxima reunião da AULP no Brasil, mostrando entusiasmo na preparação do próximo Encontro.

Após a Assembleia Geral, teve início a sessão de encerramento do XXVI Encontro da AULP. Na mesa, S. Exa. Ministro de Estado Coordenador dos Assuntos Sociais e Ministro da Educação de Timor Leste, Dr. António da Conceição, S. Exa. Secretário dos Assuntos Sociais e Cultura do Governo da RAEM, Dr. Alexis Tam Chon Weng, Secretária-Executiva da CPLP, Dra. Georgina Melo, Reitor da Universidade de Macau, Prof. Dr. Wei Zhao, Reitor da Universidade Nacional Timor Lorosa'e, Professor Doutor Francisco Martins.

Foi referido que apesar de vários países de língua portuguesa atravessarem, a nível global, um período socioeconómico desfavorável, houve muita aderência ao Encontro pelos membros institucionais da AULP.

Salientou-se que muitas dificuldades têm sido sentidas, o que naturalmente tem impacto em áreas como a educação e a investigação. Mas, apesar das dificuldades sentidas a vários níveis, o XXVI Encontro da AULP superou as expetativas.

Alguns dos presentes, para conseguirem estar no XXVI Encontro da AULP, fizeram quase 2 dias em viagem. A presença de todos neste encontro em que Timor-Leste foi palco, foi prova que obstáculos, como a distância física, são facilmente ultrapassáveis quando existe interesse pela partilha de conhecimento, 
pela melhoria da educação, em geral, e do ensino superior, em particular, e pela promoção e difusão da língua portuguesa.

Há quase 30 anos, a 26 de Novembro de 1986, o grupo de 16 dirigentes responsáveis pela criação e institucionalização da AULP, representantes de 16 instituições de ensino e investigação de nível superior, oriundos de cinco países de língua portuguesa, não poderiam prever o impacto e a força da AULP, crescente ao longo destes anos. Hoje são 142 instituições de ensino superior, não contando com as instituições parceiras ou os membros associados, 10 atualmente, constituídos por Departamentos de Estudos Portugueses, Estudos Brasileiros, de Estudos Africanos, de Estudos Latino - Americanos e de Estudos Luso - Asiáticos que, não sento total ou parcialmente de língua portuguesa, se identifiquem com os objetivos da associação e, ainda, as associações, fundações ou outras organizações que se dediquem a atividades ligadas ao Ensino Superior, Investigação e Cultura.

Na sessão de encerramento deu-se a Assinatura de um Memorando de Entendimento entre a UNTL e 29 Universidades da AULP dos vários países de língua oficial portuguesa e Macau. Uma iniciativa de promoção da cooperação lusófona, difusão da língua portuguesa e mobilidade académica.

O Professor Doutor Sebastião Feyo de Azevedo, Reitor da Universidade do Porto, anunciou nesta sessão a oferta de 3600 publicações e material desportivo à UNTL pela Universidade do Porto, tomando ainda a palavra S. Exa. Secretário de Estado da Juventude e Desporto de Timor-Leste, Dr. Leovigildo Hornay.

O Reitor da Universidade de Macau, Professor Doutor Wei Zhao, discursou em português para agradecer toda a organização do Encontro.

Por último, o anfitrião Reitor da UNTL, Professor Doutor Francisco Martins, agradeceu a presença de todos os participantes, revelando estar muito satisfeito com o resultado final deste Encontro da AULP em Timor-Leste, o primeiro em 30 anos, deixando patente que não será o último e que futuramente haverá um regresso a terras timorenses. Terminada a sessão de encerramento, foi oferecido um almoço aos participantes e finalmente uma visita cultural à Cidade de Díli.

Com o Encontro em Díli, a AULP atingiu todo o universo daqueles que reconhecem a importância da língua portuguesa como um marco distintivo da originalidade da sua cultura, e a Universidade Nacional Timor Lorosa'e, marcou com absoluta dignidade o seu espaço próprio no seio da Associação. 